\title{
New rules of consent: the patient decides
}

\author{
Fiona Godlee editor in chief, The BMJ
}

How much information should patients be given about the risks of treatment? And who decides what a patient needs to know? Until now, in the United Kingdom, doctors have been allowed to decide this, and the 30 year old Bolam test specified that their conduct would be considered acceptable if it would be supported by a responsible body of medical opinion.

But this has all just changed. Last week the UK's Supreme Court judged that it was for patients to decide whether the risks of treatment and alternative options have been adequately communicated. Nadine Montgomery, who has diabetes, was not told of the risks of shoulder dystocia to her baby boy, who subsequently developed cerebral palsy (doi:10.1136/bmj.h1414). Her obstetrician justified holding back this information on the grounds that it might have discouraged her from having a vaginal delivery.

This will no longer do. As Daniel Sokol explains (doi:10.1136/ bmj.h1481), the Montgomery ruling means that doctors will have to take "reasonable care to ensure that the patient is aware of any material risks involved in any recommended treatment and of any reasonable alternative or variant treatments." Sokol advises doctors to make extra sure that the discussion is fully documented.

What counts as a material risk? Here the Supreme Court has landed a clear and crucial blow to medical paternalism. Instead of a responsible body of medical opinion, the judgment now rests with "a reasonable person in the patient's position."

Sokol outlines the questions doctors should now ask themselves when seeking consent from patients. The result will surely be a better conversation. Some doctors will say they don't have time, but if ethics and professionalism are not enough to bring about the necessary change in attitudes and behaviour, the court is uncompromising: the law now obliges "even those doctors who have less skill or inclination for communication, or who are more hurried, to pause and engage in the discussion."

The days should be long gone when obtaining consent was left to the most junior trainee, tasked with getting the patient's signature on a standard form, like a salesperson on commission. But how well things are done will vary from person to person and place to place. These days, in the best centres, patients who are considering undergoing a major procedure or course of treatment are invited to a specialist clinic, where experts in communicating risk spend time going through the options, including the option of doing nothing.

But this is a skill that all doctors need to learn, perhaps, dare I say it, especially surgeons. So it's good to hear from Clare Marx, recently appointed president of the Royal College of Surgeons, that, along with improving the quality of surgical training, shared decision making is high on her agenda. The college's recent report Good Surgical Practice emphasises the importance of collaboration and shared decision making. In The BMJ's interview published recently (doi:10.1136/bmj.h462) Luisa Dillner, herself a former surgical trainee, asks, "Are these traditional surgical attributes?" Marx's reply: "They will be."

Cite this as: BMJ 2015;350:h1534

๑ BMJ Publishing Group Ltd 2015 